\title{
Transiting Nerve Rootlet Abnormalities on MRI after Lumbar Laminectomy: Associations with Persistent Postoperative Pain
}

\author{
Chankue Park, MD, PhD ${ }^{1}$, In Sook Lee, MD, PhD², Kyoung Hyup Nam, MD, PhD², You Seon Song, MD, PhD², \\ Tae Hong Lee, MD, PhD ${ }^{2}$, In Ho Han, MD, PhD², Dong Hwan Kim, MD
}

${ }^{1}$ Department of Radiology, Research Institute for Convergence of Biomedical Science and Technology, Pusan National University Yangsan Hospital, Yangsan, Korea; Departments of ${ }^{2}$ Radiology and ${ }^{3}$ Neurosurgery, Pusan National University Hospital, Pusan National University School of Medicine, Busan, Korea

Objective: To determine whether changes in the transiting nerve rootlet or its surroundings, as seen on MRI performed after lumbar hemilaminectomy, are associated with persistent postoperative pain (PPP), commonly known as the failed back surgery syndrome.

Materials and Methods: Seventy-three patients (mean age, 61 years; 43 males and 30 females) who underwent single-level partial hemilaminectomy of the lumbar spine without postoperative complications or other level spinal abnormalities between January 2010 and December 2018 were enrolled. Two musculoskeletal radiologists evaluated transiting nerve rootlet abnormalities (thickening, signal alteration, distinction, and displacement), epidural fibrosis, and intrathecal arachnoiditis on MRI obtained one year after the operations. A spine surgeon blinded to the radiologic findings evaluated each patient for PPP. Univariable and multivariable analyses were used to evaluate the association between the MRI findings and PPP.

Results: The presence of transiting nerve rootlet thickening, signal alteration, and ill-distinction was significantly different between the patients with PPP and those without, for both readers $(p \leq 0.020)$. Conversely, the presence of transiting nerve rootlet displacement, epidural fibrosis, and intrathecal arachnoiditis was not significantly different between the two groups $(p \geq 0.128)$. Among the above radiologic findings, transiting nerve rootlet thickening and signal alteration were the most significant findings in the multivariable analyses $(p \leq 0.009)$.

Conclusion: On MRI, PPP was associated with transiting nerve rootlet abnormalities, including thickening, signal alterations, and ill-distinction, but was not associated with epidural fibrosis or intrathecal arachnoiditis. The most relevant findings were the nerve rootlet thickening and signal alteration.

Keywords: Persistent postoperative pain; Failed back surgery; Laminectomy; Spinal nerve roots; Epidural fibrosis

\section{INTRODUCTION}

Persistent postoperative pain (PPP), the postsurgical

Received: March 3, 2020 Revised: April 19, 2020

Accepted: May 26, 2020

Corresponding author: In Sook Lee, MD, PhD, Department of Radiology, Pusan National University Hospital, Pusan National University School of Medicine, 179 Gudeok-ro, Seo-gu, Busan 49241, Korea.

- E-mail: lis@pusan.ac.kr

This is an Open Access article distributed under the terms of the Creative Commons Attribution Non-Commercial License (https://creativecommons.org/licenses/by-nc/4.0) which permits unrestricted non-commercial use, distribution, and reproduction in any medium, provided the original work is properly cited. syndrome, or, as it is more commonly known, the failed back surgery syndrome, refers to chronic back pain, with or without radicular pain, that recurs or continues in patients following lumbar spine surgery. Although the definition of PPP is not clear, the incidence of PPP is known to be $10-40 \%$ after lumbar laminectomy with or without fusion (1) and $8-19 \%$ after lumbar discectomy (2). Furthermore, the rate of lumbar laminectomies and fusions has been exponentially increasing in the United States, by $11.3 \%$ from 1998 to 2008 (3) and by $62.3 \%$ from 2004 to 2015 (4).

The causes of PPP may be divided into operative factors, including inadequate decompression of lateral recesses and foramina, instability associated with 
excessive decompression, and incorrect level surgery and postoperative factors such as recurrent disc herniation, adjacent segment disease, the battered root syndrome, or the nerve root entrapment syndrome (5). Despite postoperative MRI showing successful nerve root decompression at the correct level without recurrent disc herniation, there have been patients who continued to complain of PPP. The possible causes of such PPP include iatrogenic nerve root irritation or injury during operation and nerve root entrapment or adhesion during epidural fibrosis (5).

Lee et al. (6) reported that residual or recurrent postoperative pain was associated with nerve root enhancement, displacement, and thickening but not with epidural fibrosis. However, this study was performed using contrast-enhanced MRI due to the low-magnetic field used (83 patients at $0.5 \mathrm{~T}$ and 57 patients at $1.5 \mathrm{~T}$ ) and performed only univariable analyses, examining the relationship between each radiologic factor and each symptom, and not a comprehensive multivariable analysis. Furthermore, the American College of Radiology has recommended the use of MRI without contrast for routine evaluations of patients who present with spinal pain and a history of prior lumbar surgery (7). The relationship between epidural fibrosis and PPP after lumbar spine surgery is also controversial; some studies did report to have found a relationship between the two (8-10) but others did not $(6,11)$. High-magnetic field MRI, defined as having a field strength higher than $1 \mathrm{~T}$ (12), enables the evaluation of detailed anatomic structures such as the ventral and dorsal transiting nerve rootlet as well as the nerve root. We hypothesized that transiting nerve rootlet abnormalities or epidural fibrosis seen on MRI might be connected to PPP in patients following successful decompression surgery without complications. Thus, we aimed to determine whether changes in the transiting nerve rootlet or its surroundings, as seen on MRI performed after lumbar hemilaminectomy, are associated with PPP.

\section{MATERIALS AND METHODS}

This retrospective study was approved by the Institutional Review Board and the requirement for informed consent was waived.

\section{Study Group}

We enrolled patients who underwent single-level partial hemilaminectomy of the lumbar spine and MRI one year after the operation, and who had no postoperative complications or other level spinal abnormalities.

Five hundred and three lumbar MRI examinations were identified between January 2010 and December 2018 through a computerized search of radiology reports using the following keywords: report of "laminectomy," modality of "MRI," and anatomy of "lumbar spine." Of the 503 examinations, 238 were of patients who had undergone single-level partial hemilaminectomy of the lumbar spine. Additionally, 150 of these 238 patients underwent followup MRI at one year after the operation. Of the 150 patients, 73 patients (mean age, 61 years; age range, 28-87 years; 43 males [mean age, 60 years; range, 28-87 years] and 30 females [mean age, 63 years; range, $30-87$ years]) who had no postoperative complications or other level spinal abnormalities were included in the final analysis (Fig. 1).

\section{Clinical Outcome}

Information on age, sex, preoperative symptoms, operative date and level, MRI examination date, and spinal symptoms at the time of the MRI examination was obtained from the medical records. A spine surgeon, blinded to the radiologic data, retrospectively evaluated each patient's medical records for the presence of PPP at the operative level. PPP was defined as no significant symptom relief when compared to the preoperative symptoms. Significant symptom relief was defined as all of the following: 1) no or minimal remaining pain, 2) ability to work not adversely affected, 3) no use of analgesic medications, and 4) patient satisfaction with the procedure (13). Ambiguous low back or buttock pain unrelated to the preoperative symptoms or operative site was not defined as PPP.

\section{MRI Protocol}

MRI examinations were performed using 1.5T units (MAGNETOM Vision and Avanto, Siemens Healthineers), in 52 patients, or 3T units (MAGNETOM Skyra and Trio, Siemens Healthineers; Achieva TX, Philips Healthcare), in 21 patients. All MRI examinations included an axial T1-weighted fast spin-echo (FSE) sequence (repetition time ms/echo time ms: 500-680/10-16) and T2-weighted FSE sequence (3000-6710/81-120), with a 4-mm section thickness and a $140 \times 140-160 \times 160 \mathrm{~mm}$ field of view, and a sagittal T1weighted FSE sequence (358-767/10-15) and T2-weighted FSE sequence (2980-5082/81-134), with a 4-mm section thickness and a $250 \times 250-320 \times 320 \mathrm{~mm}$ field of view. 


\begin{tabular}{|c|c|}
\hline $\begin{array}{l}\text { Search for "laminectomy" in the radiology } \\
\text { reports of lumbar spine MRI } \\
\text { (January 2010-December 2018) } \\
\qquad(n=503)\end{array}$ & \multirow{2}{*}{$\begin{array}{l}\text { Exclusion related to operation }(n=265) \\
\text { - Posterior metal fixation: } 155 \\
\text { - Multi-level laminectomy: } 42 \\
\text { - Laminectomy for tumor removal: } 35 \\
\text { - Laminectomy for infection: } 33\end{array}$} \\
\hline$\downarrow$ & \\
\hline $\begin{array}{l}\text { Single-level partial hemilaminectomy } \\
\qquad(\mathrm{n}=238)\end{array}$ & \multirow[b]{2}{*}{$\begin{array}{l}\text { Exclusion related to imaging }(n=88) \\
\text { - MRI within } 1 \text { year from operation: } 75 \\
\text { - Multiple follow-up MRIs*: } 13\end{array}$} \\
\hline$\downarrow$ & \\
\hline $\begin{array}{l}\text { Patients underwent MRI } 1 \text { year after the operation } \\
\qquad(n=150)\end{array}$ & \multirow{3}{*}{$\begin{array}{l}\text { Exclusion related to postoperative MRI findings }(n=77) \\
\text { - Postoperative complication }(n=26) \\
\text { - Infection: } 15 \\
\text { - Recurrent disc herniation: } 11 \\
\text { - Other level spinal abnormality }(n=51) \\
\text { - Spinal stenosis: } 25 \\
\text { - Disc protrusion or extrusion: } 23 \\
\text { - Compression fracture: } 3\end{array}$} \\
\hline$\downarrow$ & \\
\hline $\begin{array}{l}\text { Patients without postoperative complications or } \\
\text { other level spinal abnormality } \\
\qquad(\mathrm{n}=73)\end{array}$ & \\
\hline
\end{tabular}

Fig. 1. Flow diagram of study patients. Within the same category, we excluded the subcategory factors in descending order. *If the patients had undergone multiple MRIs one year after the operation, only the one MRI closest to the date of the operation was selected, ${ }^{\dagger} 0$ ther level spinal abnormalities included moderate-to-severe spinal stenosis and foraminal stenosis, disc protrusion or extrusion, and fracture. A mild degree of spinal stenosis or foraminal stenosis and disc degeneration were not included in the "other level spinal abnormality" category.

\section{Image Analysis}

Two radiologists (readers 1 and 2 with 15 and 3 years of experience in musculoskeletal radiology, respectively) blinded to the clinical data retrospectively evaluated the operative level on MRI. Axial T1- and T2-weighted sequences were selected for image analysis and sagittal images were used as a supplement for the spinal level check. The readers evaluated transiting nerve rootlet abnormalities, epidural fibrosis, and intrathecal arachnoiditis.

\section{Transiting Nerve Rootlet Abnormalities}

The transiting nerve rootlet abnormalities were evaluated by looking at the ventral and dorsal nerve rootlets between the dural sac and the foraminal zone (Fig. 2). The transiting nerve rootlet abnormalities were divided into four subcategories: thickening, signal alteration, distinction, and displacement or compression $(6,14)$ (Fig. 2). Transiting nerve rootlet thickening was defined as a more than $50 \%$ increase in the diameter of the nerve rootlet at the operative site when compared with the contralateral nerve rootlet at the same level (15). A presence of a nerve rootlet signal alteration was defined as hyperintensity of the nerve rootlet when compared with the contralateral nerve rootlet at the same level on the T2-weighted sequence.
Nerve rootlet distinction was defined as follows: 1 ) welldistinction if the margin of the nerve rootlet was wellcircumscribed, sharply bordered, and well-distinct from the surrounding cerebrospinal fluid; 2) partially ill-distinction if part of the nerve rootlet margin was indistinct; and 3) completely ill-distinction if the whole nerve rootlet margin was indistinct and indistinguishable from the surrounding structures. Nerve rootlet displacement or compression was defined as present if the position of the nerve rootlet was different from what was expected or compressed when a more than $50 \%$ decrease in diameter was observed when compared with the position of the contralateral nerve rootlet at the same level (6).

\section{Epidural Fibrosis}

Epidural fibrosis was diagnosed when there was an area of intermediate or low signal intensity on a T1-weighted sequence in the epidural space that obscured or obliterated the normal high signal of the epidural fat. The amount of epidural fibrosis was graded on a scale of 1-4 for each quadrant of each imaging slice encompassing the operative level, as follows: 1 was assigned if the quadrant area showed no or minimal fibrosis, i.e., $<25 \%$ of the quadrant was filled with fibrosis, 2 if it showed $\geq 25 \%$ and $<50 \%$ 


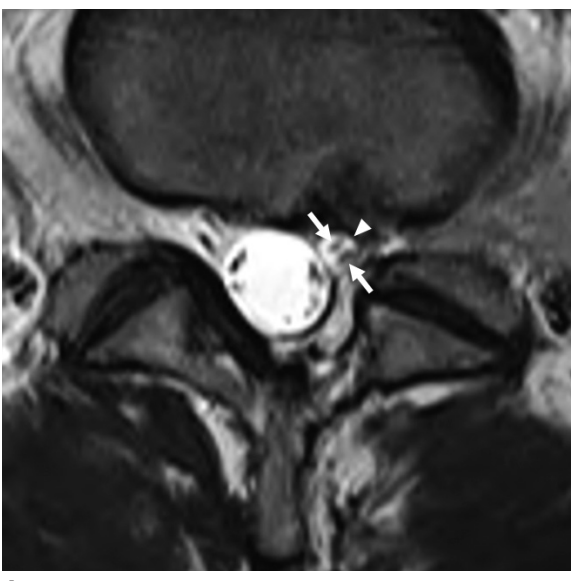

A

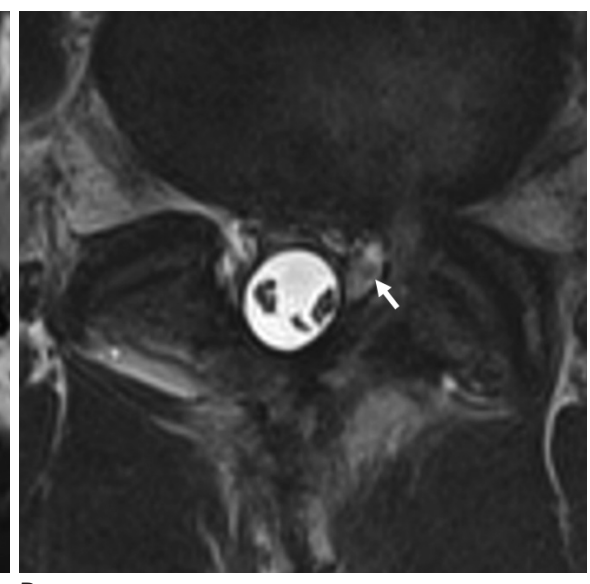

B

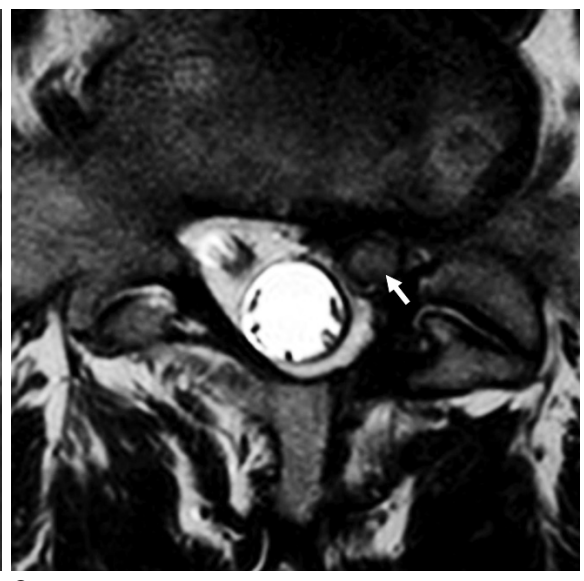

C

Fig. 2. Axial T2-weighted fast spin-echo sequences in three different patients who underwent left partial hemilaminectomy of L5-S1.

A. Transiting nerve rootlet abnormalities were evaluated by looking at the ventral and dorsal nerve rootlets (arrows) within the nerve root (arrowhead) located between the dural sac and the foraminal zone. The MR image of the L5-S1 level shows well-distinction of the transiting nerve rootlet, without size change, signal alteration, or displacement at the left operative site (arrows). B. The MR image of the L5-S1 level shows thickening, signal alteration, and partially ill-distinction of the transiting nerve rootlet at the left operative site (arrow). C. The MR image of the L5-S1 level shows thickening, signal alteration, and completely ill-distinction of the transiting nerve rootlet at the left operative site (arrow).

fibrosis, 3 if $\geq 50 \%$ and $<75 \%$, and 4 if $\geq 75 \%(8-10)$.

\section{Intrathecal Arachnoiditis}

Intrathecal arachnoiditis was defined as present if multiple nerve roots were clumped together or adhered to the margins of the thecal sac $(16,17)$. This study evaluated the intrathecal nerve roots, excluding the transiting nerve rootlets or dorsal root ganglia.

\section{Statistical Analysis}

For the analysis, the patients were divided into two groups, i.e., patients with and without PPP. The clinical information was compared between the two groups using Fisher's exact test or the $t$ test. Univariable and multivariable stepwise logistic regression models were used to evaluate the associations between the radiological findings and PPP. For the analysis, nerve rootlet distinction and epidural fibrosis were each classified into two categories because the numbers were too small for several subcategories ("normal" vs. "abnormal" defined as "well-defined" vs. "partially + completely ill-defined" for nerve rootlet distinction; "grade 1 " vs. "grade $2+3+4$ " for epidural fibrosis). Inter-reader agreement was assessed using kappa $(\kappa)$ statistics for each radiologic finding with the following scale: $0-0.20$, poor; $0.21-0.40$, fair; $0.41-0.60$, moderate; $0.61-0.80$, good; and 0.81-1.00, excellent (18).

The analyses were performed using the SPSS for Windows software (version 21.0, IBM Corp.) and differences with $p$
Table 1 Patient Demographics

\begin{tabular}{lccc}
\hline \multicolumn{1}{c}{ Category } & No PPP & PPP & $P$ \\
\hline Mean age (CI), years & $62(58,66)$ & $60(55,64)$ & 0.447 \\
Sex & & & 0.345 \\
$\quad$ Male & 22 & 21 & \\
$\quad$ Female & 19 & 11 & \\
Operative level* & & 1.000 \\
L3-4 & 3 & 13 & \\
L4-5 & 16 & 13 & \\
L5-S1 & 22 & & \\
Mean time interval between & & $20(14,26)$ & 0.367 \\
operation and MRI (CI), & $19(13,26)$ & & \\
month & & 32 & \\
Total number of patients & 41 &
\end{tabular}

*The analysis of the operation level was only a comparison between L4-5 and L5-S1, excluding L3-4 due to small sample size. $95 \% \mathrm{CI}=95 \%$ confidence interval, $\mathrm{PPP}=$ persistent postoperative pain

values $<0.05$ were considered statistically significant.

\section{RESULTS}

Among the 73 patients, 41 had no PPP and 32 had PPP. The clinical information, including the patient age, sex, operative level, and mean time interval between the operation and the MRI, was not significantly different between the patients with and those without PPP ( $p \geq$ 0.345 ) (Table 1). The preoperative diagnosis was either herniated disc $(n=56)$ or spinal stenosis $(n=17)$. Most 
patients underwent follow-up MRI for symptoms such as radiculopathy, leg weakness, or back or buttock pain $(94.5 \%$, $\mathrm{n}=69$ ) and four patients underwent MRI to screen for possible postoperative complications.

The results of the associations between the MRI findings and PPP are summarized in Table 2. Among the radiologic findings, the presence of nerve rootlet thickening, signal alteration, and ill-distinction were significantly different between the patients with and those without PPP for both readers $(p \leq 0.020)$ (Fig. 3 ). Nerve rootlet thickening was more common in the PPP group than in the non-PPP group \{non-PPP vs. PPP: $16 / 41$ (39.0\%) vs. $24 / 32$ (75.0\%) for reader 1 ( $p=0.003$; odds ratio [95\% confidence interval, $95 \% \mathrm{CI}], 4.687$ [1.696-12.959]) and 13/41 (31.7\%) vs. $19 / 32(59.4 \%)$ for reader 2 ( $p=0.020$; odds ratio [95\% CI], 3.148 [1.200-8.259])\}. The presence of signal alteration was significantly different between the groups \{non-PPP vs. PPP: $19 / 41(46.3 \%)$ vs. $24 / 32(75.0 \%)$ for reader 1 $(p=0.016$; odds ratio [95\% CI], 3.474 [1.267-9.523]) and $14 / 41(34.1 \%)$ vs. $21 / 32(65.6 \%)$ for reader $2(p=$ 0.009 ; odds ratio [95\% CI], 3.682 [1.390-9.752])\}. The frequency of "ill-distinction" was higher than that of "welldistinction" in the PPP group \{non-PPP vs. PPP: $13 / 41$ (31.7\%) vs. 20/32 (62.5\%) for reader 1 ( $p=0.010$; odds ratio $[95 \% \mathrm{CI}], 3.590[1.358-9.489])$ and $14 / 41(34.1 \%)$ vs. $20 / 32(62.5 \%)$ for reader 2 ( $p=0.018$; odds ratio [95\% CI], 3.214 [1.226-8.426])\}. Conversely, the presence of nerve rootlet displacement or compression ( $p=0.128$ for reader 1 and 0.999 for reader 2$)$, epidural fibrosis ( $p=$ 0.202 for reader 1 and 0.890 for reader 2$)$, and intrathecal arachnoiditis ( $p=0.964$ for reader 1 and 0.564 for reader 2) was not significantly different between the two groups for both readers. The most common epidural fibrosis was grade 1. Inter-reader agreement was moderate-to-good for nerve rootlet thickening, signal alteration, distinction, displacement or compression, and epidural fibrosis $(\kappa=$ $0.483-0.685)$ and fair for arachnoiditis $(\kappa=0.316)$. In the multivariable regression analysis, the transiting nerve rootlet

Table 2. Association between Radiologic Findings and PPP

\begin{tabular}{|c|c|c|c|c|c|c|c|c|c|}
\hline \multirow{2}{*}{ MRI Findings } & \multicolumn{4}{|c|}{ Reader 1} & \multicolumn{4}{|c|}{ Reader 2} & \multirow{2}{*}{$\kappa$} \\
\hline & No PPP & PPP & $P$ & Odds Ratio & No PPP & PPP & $P$ & Odds Ratio & \\
\hline \multicolumn{10}{|l|}{ NR abnormalities } \\
\hline Thickening & & & 0.003 & 4.687 & & & 0.020 & 3.148 & 0.483 \\
\hline Absent & 25 & 8 & & & 28 & 13 & & & \\
\hline Present & 16 & 24 & & & 13 & 19 & & & \\
\hline Signal alteration & & & 0.016 & 3.474 & & & 0.009 & 3.682 & 0.565 \\
\hline Absent & 22 & 8 & & & 27 & 11 & & & \\
\hline Present & 19 & 24 & & & 14 & 21 & & & \\
\hline Distinction* & & & 0.010 & 3.590 & & & 0.018 & 3.214 & 0.547 \\
\hline Well & 28 & 12 & & & 27 & 12 & & & \\
\hline Partially ill & 11 & 16 & & & 9 & 15 & & & \\
\hline Completely ill & 2 & 4 & & & 5 & 5 & & & \\
\hline Displacement & & & 0.128 & 5.714 & & & 0.999 & NA & 0.554 \\
\hline Absent & 40 & 28 & & & 41 & 30 & & & \\
\hline Present & 1 & 4 & & & 0 & 2 & & & \\
\hline Epidural fibrosis* & & & 0.202 & 1.880 & & & 0.890 & 1.069 & 0.685 \\
\hline Grade 1 & 29 & 18 & & & 25 & 19 & & & \\
\hline Grade 2 & 5 & 4 & & & 9 & 2 & & & \\
\hline Grade 3 & 4 & 5 & & & 4 & 5 & & & \\
\hline Grade 4 & 3 & 5 & & & 3 & 6 & & & \\
\hline Arachnoiditis & & & 0.964 & 1.022 & & & 0.564 & 0.715 & 0.316 \\
\hline Absent & 22 & 17 & & & 31 & 26 & & & \\
\hline Present & 19 & 15 & & & 10 & 6 & & & \\
\hline Total & 41 & 32 & & & 41 & 32 & & & \\
\hline
\end{tabular}

Data are number of patients. $P$ values and odds ratios were calculated with logistic regression analysis. * For analysis, nerve rootlet distinction and epidural fibrosis were each classified into two categories ("normal" vs. "abnormal": "well-defined" vs. "partially + completely ill-defined" for distinction; "grade 1 " vs. "grade $2+3+4$ " for epidural fibrosis). NA = not applicable, NR = transiting nerve rootlet 


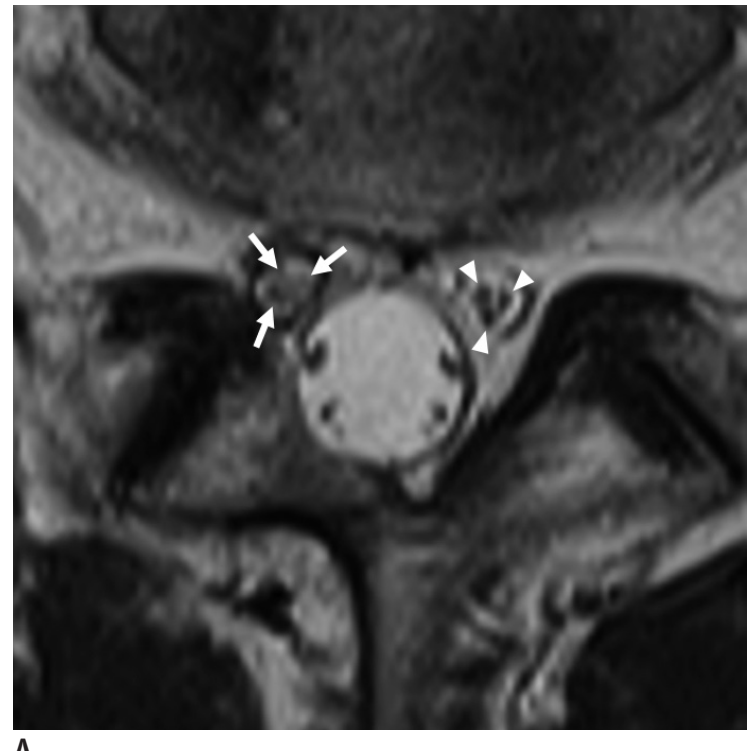

A

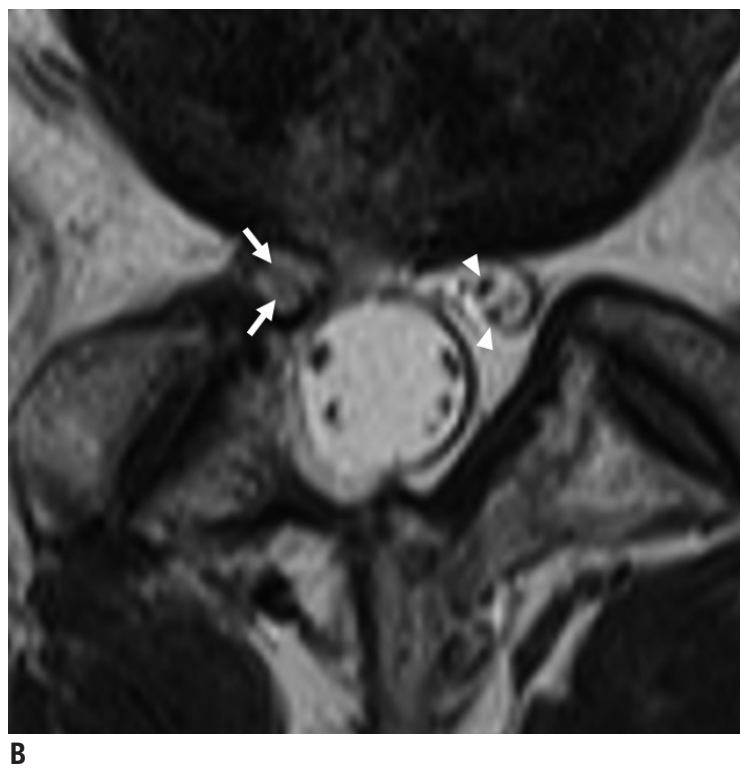

Fig. 3. 61-year-old male presenting with persistent postoperative pain after right partial hemilaminectomy of L5-S1.

Axial T2-weighted fast spin-echo sequence images (two consecutive slices: A, B) show the thickening, signal alteration, and ill-distinction of the transiting nerve rootlet (arrows) at the operative site, compared with the contralateral transiting nerve rootlet (arrowheads).

thickening ( $p=0.002$; odds ratio [95\% CI], 4.687 [1.6969.489]) and signal alteration ( $p=0.009$; odds ratio [95\% $\mathrm{CI}], 3.682$ [1.390-9.752]) were the findings most strongly associated with PPP.

\section{DISCUSSION}

PPP is an adverse surgical outcome of lumbar disc surgery that may result from many different possible mechanisms and, therefore, present with many different radiologic findings. Patients often complain of persistent back pain or sciatica, regardless of the presence or absence of neural compression. Our study suggests that the thickening, signal alteration, and ill-distinction of the transiting nerve rootlet, observed on MRI, are significantly associated with PPP. Among the radiologic findings, the nerve rootlet thickening and signal alteration were the findings associated the most with PPP. However, we found no association between epidural fibrosis or intrathecal arachnoiditis and PPP.

To our knowledge, this approach, of evaluating the association between the characteristics of the transiting nerve rootlet, but not the nerve root, and PPP, is a novel one. One study investigated the association between nerve root abnormalities and PPP, showing an association between nerve root enhancement, thickening, and displacement and PPP (6). However, that study investigated the correlation between the symptoms and nerve root changes shown on contrast-enhanced T1-weighted images, due to the low magnetic field used. Nevertheless, recently developed highfield MR that reveals detailed anatomical features can be used to evaluate the size, signal intensity, and margin of nerve rootlets. Furthermore, the American College of Radiology has recommended MRI without contrast for routine evaluations of patients who present with spinal pain and a history of prior lumbar surgery (7). Although we included several patients who underwent contrast-enhanced MRI, we only evaluated the non-contrast-enhanced images for the purposes of this study. The multivariable analyses in our study showed that transiting nerve rootlet thickening and signal alteration were the most relevant factors associated with PPP. We suggest naming these findings the "nerve rootlet swelling sign." We speculate that despite the successful decompression of the nerve root, the nerve rootlet abnormalities noted on MRI might be due to intraoperative dural sleeve tears, nerve rootlet irritation, or the sequelae of previous nerve compression and that these might be associated with PPP.

Epidural fibrosis following lumbar surgery has been reported to occur in $10 \%$ to $75 \%$ of cases $(8,13)$ and PPP was associated with $10 \%$ to $24 \%$ of these epidural fibrosis cases (13). Although the exact mechanism of fibrosis formation has not been established, fibrosis-induced pain can be caused by the inflammation, compression, and traction of the fibrotic tissue on adjacent nerve roots (19, 20). Our results show that neither epidural fibrosis nor nerve rootlet displacement or compression was associated 
with PPP. Some authors have described epidural fibrosis as a cause of PPP (8-10) but other authors have opposed this opinion $(6,11)$. The contrasting conclusions in these studies may have resulted from their different definitions of epidural fibrosis, depending on the extent of epidural fibrotic tissue or compression of the thecal sac. Considering our results, transiting nerve rootlet swelling appears to be associated with PPP regardless of the existence of epidural fibrosis or nerve rootlet displacement. Therefore, it is important to focus on the transiting nerve rootlet itself in axial T2-weighted sequence images when evaluating the MRI images of patients with PPP.

Arachnoiditis is a form of leptomeningeal and neural inflammation within the spinal canal. Arachnoiditis may be caused by varying triggers, including intradural surgery or dural tears, meningitis, subarachnoid hemorrhage, or injections; however, in many cases of arachnoiditis, the cause remains idiopathic $(16,21)$. Sterile arachnoiditis has been reported to cause persistent pain in $6-16 \%$ of postoperative cases (22). The inter-reader agreement in our study was fair for the evaluation of arachnoiditis and moderate-to-good for other radiologic factors. The relatively low inter-reader agreement in our study occurred because the evaluation of adhering nerve roots was ambiguous in some mild cases. However, in both of the readers' assessments, the presence of intrathecal arachnoiditis was not associated with PPP.

Our study has several limitations. First, we did not analyze the preoperative MRI findings. Comparing preand post-operative MRI findings could result in a more accurate radiologic evaluation. Second, although a spine surgeon independently determined the presence of PPP, quantitative pain scores such as the Oswestry Disability Index or a functional score were not included in the analysis. Third, the asymptomatic patients were much less likely to perform MRI than the patients with PPP. There is, therefore, a possibility of selection bias. Fourth, although we evaluated the nerve rootlet changes and epidural fibrosis with reference to the contralateral side, some cases were ambiguous to judge. If an MR neurography would have been added, evaluation could have been more accurate (23).

In conclusion PPP was associated with transiting nerve rootlet abnormalities, including thickening, signal alterations, and ill-distinction, but not with epidural fibrosis or intrathecal arachnoiditis. The most relevant findings were the nerve rootlet thickening and signal alteration. If pain persists in patients after lumbar spine surgery, it is recommended to check for transiting nerve rootlet abnormalities on MRI.

\section{Conflicts of Interest}

The authors have no potential conflicts of interest to disclose.

$$
\begin{aligned}
& \text { ORCID iDs } \\
& \text { Chankue Park } \\
& \text { https://orcid.org/0000-0003-2937-114X } \\
& \text { In Sook Lee } \\
& \text { https://orcid.org/0000-0001-7295-600X } \\
& \text { Kyoung Hyup Nam } \\
& \text { https://orcid.org/0000-0002-3749-4660 } \\
& \text { You Seon Song } \\
& \text { https://orcid.org/0000-0002-8948-5133 } \\
& \text { Tae Hong Lee } \\
& \text { https://orcid.org/0000-0001-5911-5214 } \\
& \text { In Ho Han } \\
& \text { https://orcid.org/0000-0001-7193-6533 } \\
& \text { Dong Hwan Kim } \\
& \text { https://orcid.org/0000-0001-8982-7917 }
\end{aligned}
$$

\section{REFERENCES}

1. Chan C, Peng P. Failed back surgery syndrome. Pain Med 2011;12:577-606

2. Shamim MS, Parekh MA, Bari ME, Enam SA, Khursheed F. Microdiscectomy for lumbosacral disc herniation and frequency of failed disc surgery. World Neurosurg 2010;74:611616

3. Rajaee SS, Bae HW, Kanim LE, Delamarter RB. Spinal fusion in the United States: analysis of trends from 1998 to 2008. Spine (Phila Pa 1976) 2012;37:67-76

4. Martin BI, Mirza SK, Spina N, Spiker WR, Lawrence B, Brodke DS. Trends in lumbar fusion procedure rates and associated hospital costs for degenerative spinal diseases in the United States, 2004 to 2015. Spine (Phila Pa 1976) 2019;44:369-376

5. Sebaaly A, Lahoud MJ, Rizkallah M, Kreichati G, Kharrat K. Etiology, evaluation, and treatment of failed back surgery syndrome. Asian Spine J 2018;12:574-585

6. Lee YS, Choi ES, Song CJ. Symptomatic nerve root changes on contrast-enhanced MR imaging after surgery for lumbar disk herniation. AJNR Amn J Neuroradiol 2009;30:1062-1067

7. Patel ND, Broderick DF, Burns J, Deshmukh TK, Fries IB, Harvey $\mathrm{HB}$, et al. ACR appropriateness criteria low back pain. J Am Col Radiol 2016;13:1069-1078

8. Coskun E, Süzer T, Topuz 0, Zencir M, Pakdemirli E, Tahta K. Relationships between epidural fibrosis, pain, disability, and psychological factors after lumbar disc surgery. Eur Spine $\mathrm{J}$ 
$2000 ; 9: 218-223$

9. Maroon J, Abla A, Bost J. Association between peridural scar and persistent low back pain after lumbar discectomy. Neurol Res 1999;21:S43-S46

10. Ross JS, Robertson JT, Frederickson RC, Petrie JL, Obuchowski $\mathrm{N}$, Modic MT, et al. Association between peridural scar and recurrent radicular pain after lumbar discectomy: magnetic resonance evaluation. Neurosurgery 1996;38:855-863

11. Annertz M, Jönsson B, Strömqvist B, Holtås S. No relationship between epidural fibrosis and sciatica in the lumbar postdiscectomy syndrome. A study with contrastenhanced magnetic resonance imaging in symptomatic and asymptomatic patients. Spine (Phila Pa 1976) 1995;20:449453

12. Marques JP, Simonis FF, Webb AG. Low-field MRI: an MR physics perspective. J Magn Reson Imaging 2019;49:15281542

13. Mohi Eldin MM, Abdel Razek NM. Epidural fibrosis after lumbar disc surgery: prevention and outcome evaluation. Asian Spine J 2015;9:370-385

14. Weber C, Kvistad KA, Moholdt VA, Nygaard ØP, Solheim 0 . Repeated 3.0 tesla magnetic resonance imaging after clinically successful lumbar disc surgery. Spine (Phila Pa 1976) $2016 ; 41: 239-245$

15. Grane P, Tullberg T, Rydberg J, Lindgren L. Postoperative lumbar MR imaging with contrast enhancement: comparison between symptomatic and asymptomatic patients. Acta Radiol 1996;37:366-372

16. Delamarter RB, Ross JS, Masaryk TJ, Modic MT, Bohlman HH. Diagnosis of lumbar arachnoiditis by magnetic resonance imaging. Spine (Phila Pa 1976) 1990;15:304-310

17. Ross JS, Masaryk TJ, Modic MT, Delamater R, Bohlman H, Wilbur G, et al. MR imaging of lumbar arachnoiditis. AJR Am J Roentgenol 1987;149:1025-1032

18. Landis JR, Koch GG. The measurement of observer agreement for categorical data. Biometrics 1977;33:159-174

19. Herrera Herrera I, Moreno de la Presa R, González Gutiérrez R, Bárcena Ruiz E, García Benassi JM. Evaluation of the postoperative lumbar spine. Radiologia 2013;55:12-23

20. Robertson JT. Role of peridural fibrosis in the failed back: a review. Eur Spine J 1996;5:S2-S6

21. Anderson TL, Morris JM, Wald JT, Kotsenas AL. Imaging appearance of advanced chronic adhesive arachnoiditis: a retrospective review. AJR Am J Roentgenol 2017;209:648-655

22. Van Goethem J, Parizel P, Jinkins J. Review article: MRI of the postoperative lumbar spine. Neuroradiology 2002;44:723-739

23. Dessouky R, Khaleel M, Khalifa DN, Tantawy HI, Chhabra A. Magnetic resonance neurography of the lumbosacral plexus in failed back surgery syndrome. Spine (Phila Pa 1976) 2018; $43: 839-847$ 